\title{
Desafios e perspectivas da contabilidade agrícola: um olhar sobre os pequenos produtores rurais do município de Tanque D'Arca
}

\author{
Maria do Rosário da Silva ${ }^{1}$ \\ Leane da Conceição Santos ${ }^{2}$ \\ Marcos Igor da Costa Santos
}

Resumo: A contabilidade rural vem se desenvolvendo no decorrer dos anos e muito se fala da sua necessidade nas instituições e na sua importância para a modernidade desse setor. No cenário do cultivo das terras, a agricultura familiar se destaca em proporção de produtores e também por sua importância na geração de emprego para os que cultivam a terra como meio de renda e subsistência. Portanto, o produtor rural precisa conhecer e se apossar dos conceitos e técnicas ligadas à contabilidade rural, levando em conta o cenário competitivo do mercado empresarial em qualquer ramo de negócio. Este trabalho, portanto, tem por objetivo mostrar a realidade dos pequenos produtores rurais em relação às dificuldades enfrentadas acerca da contabilidade e sua utilização, analisando os conceitos e conhecimentos sobre sua relevância por partes desses pequenos agricultores. Objetiva também, verificar a percepção do produtor rural quanto à mensuração, a formação de preço de venda e evidenciação de sua produção. Como base para esta pesquisa, foram selecionados pequenos produtores rurais do interior da Cidade de Tanque D'Arca, no Agreste de Alagoas. Para tanto, a metodologia desenvolvida tem característica exploratória e descritiva, com abordagem quantitativa, utilizando-se de questionário semiestruturado aplicado entre os pequenos agricultores. A pesquisa evidenciou que a agricultura familiar é escassa de informações direcionadas à contabilidade, ao controle e gerenciamento da sua atividade econômica.

Palavras-chave: Agricultura Familiar. Contabilidade Rural. Produtor Rural.

\begin{abstract}
Rural accounting has been developing over the years and much is said about its need in institutions and its importance for the modernity of this sector. In the land cultivation scenario, family farming stands out in proportion to producers and also in its importance in generating employment for those who cultivate the land as a means of income and subsistence. Therefore, farmers need to know and get hold of the concepts and techniques related to rural accounting, taking into account the competitive scenario of the business market under any business line. This paper, therefore, aims to show the reality of small farmers in relation to the difficulties faced about accounting and its use, analyzing the concepts and knowledge about its relevance by these small farmers. It also aims at the perception of rural producers regarding the measurement, formation of sale price and disclosure of their production. As a basis for this research was selected small farmers in the interior of the city of TanqueD'Arca, in Agreste de Alagoas. Therefore, the developed methodology has exploratory and descriptive characteristics with quantitative approach, using a semi-structured questionnaire with small farmers. The research showed that family farming is scarce of information directed to accounting, control and management of its economic activity.
\end{abstract}

Keywords: Family farming. Rural accounting. Rural producer.

\footnotetext{
${ }^{1}$ Graduada em Ciências Contábeis pela Universidade Estadual de Alagoas (UNEAL). Mestra em Controladoria pela Universidade Federal Rural de Pernambuco (UFRPE). Professora de Contabilidade da Faculdade de Limoeiro-PE (FACAL). E-mail: mariacont.silva@gmail.com.

2 Graduada em Ciências Contábeis pela Universidade Federal de Alagoas (UFAL). E-mail: santosleane@hotmail.com.

3 Graduado em Ciências Contábeis pelo Centro Universitário de João Pessoa (UNIPÊ). Mestre em Ciências Contábeis Pelo Multi-institucional UNB/UFPB/UFRN. Doutorando em Ciências Contábeis pela Universidade Federal da Paraíba (UFPB). Professor Assistente da Universidade Federal de Alagoas (UFAL). E-mail: marcosigor2508@gmail.com.
} 
Introdução

Diante de um cenário baseado em transformações, em especial pela globalização e abertura econômica na década de 1990, a agricultura passou por grandes modificações, e o produtor rural, a necessitar de maiores conhecimentos e agilidade na busca pela competitividade e, por que não dizer, pela sua sobrevivência.

Segundo informações da Secretaria Especial de Agricultura Familiar e do Desenvolvimento Agrário (SEAD), a agricultura familiar possui uma dinâmica e características próprias, bastante distintas, se comparadas à agricultura não familiar (SEAD, 2016). Nesta, a gestão da propriedade é compartilhada e dividida por toda família e a atividade produtiva agropecuária se torna a principal fonte geradora de renda.

$\mathrm{O}$ agricultor familiar, conforme a SEAD, tem uma relação particular em relação à terra, o seu local de trabalho e moradia. A diversidade produtiva também constitui uma característica marcante nesse setor. A Lei n ${ }^{\circ}$ 11.326, de 24 de julho de 2006, define as diretrizes para a formulação da Política Nacional da Agricultura Familiar e os critérios para a sua devida identificação.

De acordo com dados da SEAD (2016), a agricultura familiar constitui a base econômica de $90 \%$ dos municípios brasileiros com até 20 mil habitantes. Essa forma de produção responde por $35 \%$ do Produto Interno Bruto Nacional, e absorve $40 \%$ da população economicamente ativa do país. Ainda segundo o censo, a agricultura familiar é responsável pela produção, no Brasil: mandioca, 87\%; feijão, $70 \%$; milho, $46 \%$; café, $38 \%$; arroz, $34 \%$ e trigo, $21 \%$.

Portanto, é notória a importância econômica da agricultura familiar, a qual está vinculada ao abastecimento do mercado interno e ao controle da inflação dos alimentos consumidos pelos brasileiros.

Em 2017, o ramo agrícola obteve 69,4 \% de participação no PIB do agronegócio. Para 2018, a estimativa é de $72,6 \%$ de participação, portanto, um importante segmento no PIB do agronegócio (CEPEA/ESALQ-USP, 2018).

De acordo com o Ministério do Desenvolvimento Agrário (MDA), a agricultura familiar representa um importante segmento para o desenvolvimento do Brasil (MDA, 2017). De maneira aproximada, são 4,4 milhões de famílias agricultoras no país, o que representa $84 \%$ dos estabelecimentos rurais. É da agricultura familiar que vem $38 \%$ do valor bruto da produção agropecuária e o setor responde por sete em cada dez postos de trabalho no campo, se tornando cada vez mais produtiva, pois é responsável pela produção de mais de $50 \%$ dos alimentos da cesta básica brasileira.

Segundo Araújo (2003), um dos desafios ainda enfrentados pela agricultura é o não conhecimento do agronegócio, ou seja, da importância de se conhecer os outros segmentos localizados a jusante e a montante da propriedade. Por meio desse conhecimento, é possível conseguir melhores resultados, com a diminuição dos custos de produção e a obtenção de melhores preços dos seus produtos.

Lima, Basso e Neumann (2005) e Badejo (2005) corroboram a ideia de que o pequeno produtor não consegue responder a critérios simples de otimização. Com base nesses critérios, as decisões são baseadas, em sua maioria, no bom senso e no conhecimento empírico. O produtor passa a agir e a gerir seu sistema de produção conferindo-lhe uma lógica, uma racionalidade que lhe é própria, condicionada 
por um ambiente físico, social, cultural, institucional, político e econômico, e que não se determina em função da lucratividade, mas em decorrência da satisfação social ou mesmo da subsistência da família.

Em meio a isso, a contabilidade ainda é um dos instrumentos menos utilizados pelos produtores rurais, uma vez que é considerada uma técnica muito complexa, uma ferramenta pela qual os produtores não demonstram interesse. A contabilidade da produção é, portanto, colocada em segundo plano (CREPALDI, 2006).

Cabe notar que a Contabilidade Rural tem sua relevância e utilidade. Trata-se de um grande instrumento do processo de tomada de decisões, com vantagens e benefícios. A sua implantação adequada utilização proporcionará aos gestores mais eficiência e melhoria significativa da lucratividade e rentabilidade.

Seguindo esse pensamento, os estabelecimentos rurais devem buscar usufruir das vantagens socioeconômicas, as quais tendem a fortalecer sua dinâmica produtiva, especialmente no que se refere aos sistemas produtivos de pequeno porte (VEIGA, 2002).

Portanto, assim como os demais profissionais, os produtores rurais devem ter também preocupações quando se trata de custos, lucratividade e planejamento. Diante desse fato, é fundamental observar se a Contabilidade Rural está sendo vista como um importante instrumento para o processo de tomada de decisão, com a percepção dos pequenos produtores rurais quanto à mensuração e evidenciação de sua produção agrícola.

Nessa perspectiva, a pesquisa em tela repousará na seguinte questão problema: qual a percepção dos pequenos produtores rurais do município de Tanque D'Arca, Alagoas, em relação à Contabilidade Agrícola e à sua utilização?

Assim, o objetivo da pesquisa é fazer uma análise acerca da contabilidade e sua utilização nas pequenas propriedades rurais. Para alcançar essa proposta é necessário analisar, com base em conceitos da própria contabilidade, se os pequenos produtores possuem conhecimentos sobre a relevância dessa ciência e verificar se esses agricultores utilizam algum procedimento contábil para poder suprir suas necessidades de planejar, orçar e organizar.

O estudo justifica-se pela representatividade das atividades rurais em um contexto socioeconômico, como também pela relevância de se utilizar da contabilidade como um instrumento de apoio ao processo de tomada de decisão nas propriedades rurais, principalmente aquelas de pequeno porte, visando o seu crescimento e continuidade. Além, é claro, de trazer novos construtos sobre a temática perante a literatura.

\section{Referencial teórico}

\section{Agricultura familiar e de subsistência}

A agricultura familiar é uma das formas de produção na qual predomina a interação entre gestão e trabalho. São os agricultores que dirigem todo o processo produtivo, enfatizando a diversificação e se utilizando do trabalho familiar. 
A Lei n ${ }^{\circ}$ 11.326, de 24 de julho de 2006, estabelece as diretrizes para a formulação da Política Nacional da Agricultura Familiar e Empreendimentos Familiares Rurais. Consideram-se agricultor familiar e empreendedor familiar rural qualquer um que não detenha área maior do que quatro módulos fiscais; que utilize a mão de obra da própria família nas atividades econômicas de seu estabelecimento ou empreendimento; que possua renda familiar originada de atividades vinculadas ao próprio estabelecimento e dirija seu empreendimento com a sua família.

Conforme o MDA (2017), no Plano Safra 2017/2020, a agricultura familiar é um importante segmento para o desenvolvimento do Brasil, são aproximadamente 4,4 milhões de famílias, o que representa $84 \%$ dos estabelecimentos rurais. É considerada um setor econômico, porque responde por $38 \%$ do valor bruto da produção agropecuária e por sete em cada dez postos de trabalho no campo.

O Programa Nacional de Fortalecimento da Agricultura Familiar (PRONAF), principal apoiador da agricultura familiar, tem o objetivo de promover o desenvolvimento sustentável da agricultura familiar. Por meio dele, agricultores e familiares podem acessar várias linhas de crédito, de acordo como sua necessidade e projeto, podendo este último ser destinado para o custeio da safra, a atividade agroindustrial.

O PRONAF é, portanto, o programa nacional de fomento a esse tipo de atividade no país. A agricultura familiar se tornou uma categoria consagrada, capaz de abranger todas as formas de agricultura, baseada na união entre trabalho, família e produção. Esse programa representou um salto significativo em relação às políticas anteriormente praticadas, na medida em que afirmou o reconhecimento da condição de agricultor e da contribuição essencial para a sociedade, daqueles que até então eram tidos apenas como pequeno, de baixa renda ou de subsistência (WANDERLEY; SILVA; LEAL, 2012).

A sociedade, ao longo do tempo, passou a ter mais necessidade, despertando maior interesse por uma gestão rural, para que se possa ter um maior controle de suas ações, como decidir, o quê, quando e como produzir, e avaliar com mais eficiência e eficácia os seus resultados (SANTOS; MARION; SEGATTI, 2002).

Contudo, o pequeno produtor não consegue responder a critérios simples de otimização, uma vez que suas decisões são baseadas no uso do bom senso e no conhecimento empírico. Dessa maneira, passa a agir e a controlar seu sistema de produção como uma lógica, uma racionalidade que lhe é própria, condicionada por um ambiente físico, social, cultural, institucional, político e econômico (LIMA; BASSO; NEUMANN, 2005).

Portanto, conforme Badejo (2005), a tomada de decisão do pequeno produtor rural está baseada em uma racionalidade própria que não se determina apenas em função da lucratividade, mas também em decorrência da satisfação social ou até mesmo da subsistência da familia.

Segundo Polato (2006), o produtor rural precisa dar mais espaço ao empresário rural, seja planejado, buscando conhecimentos, estando atento aos riscos e entendendo sobre o funcionamento dos mecanismos de comercialização, com a finalidade de fazer que a sua empresa cresça com uma maior sustentabilidade, pois o bom planejamento e monitoramento é que irão oferecer ao produtor um crescimento com segurança. 
Contudo, é notório que a agricultura familiar é sempre lembrada por sua importância na produção de alimentos, especialmente voltada para o autoconsumo e também para a geração de renda, ou seja, seu foco principal é estar nas funções de caráter social e econômica das famílias de baixa renda.

\section{Contabilidade rural}

O desenvolvimento da contabilidade esteve ligado, de maneira íntima, ao desenvolvimento econômico, as transações sociopolíticas e socioculturais vividas em cada época, e, com o passar dos tempos, o homem foi sentindo a necessidade de aperfeiçoar o seu instrumento de avaliação da situação patrimonial, à medida que as atividades econômicas foram se tornando mais complexas (NAGATSUKA; TELES, 2002).

Para Calderelli (2003), a contabilidade rural tem suas normas baseadas na orientação, controle e registro dos atos e fatos ocorridos e praticados por uma empresa, cujo objeto de comércio ou indústria seja agricultura ou pecuária. Isso evidencia que a ciência contábil possui uma aplicação também no ambiente rural e, por esse motivo, pode atuar em conjunto com as empresas rurais, não servindo apenas de ferramenta para o cumprimento de obrigações fiscais, mas de instrumento de apoio à própria gestão.

A Contabilidade Rural tem, portanto, a seguinte finalidade: orientar as operações agrícolas e pecuárias, medindo o desempenho econômico-financeiro da empresa e de cada atividade produtiva individualmente; controlar as transações financeiras, com apoio às tomadas de decisões e auxílio às projeções de fluxos de caixa e necessidades de créditos, o que possibilita fazer a comparação da performance da empresa no tempo, e desta com outras empresas. Ajuda também a conduzir as despesas pessoais do proprietário rural e de sua família (CREPALDI, 2005).

Evidenciando esse conceito, Marion (2010) mostra que a contabilidade rural é a contabilidade geral aplicada em empresas rurais, tal como acontece em outros ramos específicos dessa ciência.

Logo, a contabilidade é uma importante ferramenta para a tomada de decisões, indispensável à administração moderna e à gestão de negócios. Portanto, a gestão das empresas ou do patrimônio da pessoa física deve considerar todos os dados fornecidos pela contabilidade no momento da decisão (RODRIGUES et al., 2012).

Crepaldi (2012) mostra que a Contabilidade Rural no Brasil ainda é pouco utilizada por empresários e contadores. Isso acontece devido ao desconhecimento por parte desses empresários da importância das informações obtidas por meio da contabilidade, da maior segurança e clareza que tais informações proporcionariam à tomada de decisões.

Diante disso, podemos afirmar que a contabilidade rural é de grande importância para o melhor desenvolvimento das atividades rurais, já que, com o controle do patrimônio, a tomada de decisões e a gerência de recursos tornam-se mais fáceis e efetivas, podendo, assim, melhorar significativamente os resultados alcançados com as atividades rurais, como afirmam Lima, Basso e Neumann (2005). 
Percebe-se que, mesmo sendo um instrumento importante para a gestão de empresas rurais, a Contabilidade Rural ainda não possui a devida valorização dos empresários, tanto pela falta de conhecimento da área contábil quanto pelo conservadorismo.

Diante disso, compreendemos a necessidade de a Contabilidade Rural ajudar nas operações agrícolas e pecuárias, ou seja, em todas as operações financeiras da organização, utilizando, para isso, métodos de mensuração. Nessa perspectiva, a orientação técnica tem um papel fundamental para auxiliar os produtores rurais no controle das informações contábeis. Assim, contribuindo com essa temática, o Comitê de Pronunciamento Contábeis (CPC) 29 - Ativos Biológicos de 2009 - enfoca a definição, mensuração e outros pontos relevantes desse tipo de ativo dentro da atividade rural.

Assim, o CPC 29 (2009, p. 06), no item 10, indica que "a entidade deve reconhecer um ativo biológico ou um produto agrícola quando controla o ativo como resultado de eventos passados; for provável que benefícios econômicos futuros associados com o ativo fluirão para a entidade e quando o valor justo ou o custo do ativo puder ser mensurado confiavelmente".

O pronunciamento contábil deixa de maneira evidente em seu texto que ativos biológicos devem ser mensurados pelo seu valor justo. O CPC 29 (2009), em seu item 9, conceitua também o valor justo como o preço que seria recebido pela venda de um ativo ou que seria pago pela transferência de um passivo em uma transação não forçada entre participantes do mercado na data de mensuração.

A avaliação pelo valor justo tem a capacidade de incorporar todas as condições de mercado, o que proporciona informações úteis e relevantes para a tomada de decisão, mesmo que apresente um maior grau de subjetividade, devido às estimativas para mensuração (AMARO; SOUZA; DA SILVA, 2016).

Contudo, em seu item 30, o CPC 29 (2009) assevera que a mensuração a valor justo não pode ser realizada de maneira confiável, deve-se utilizar o método de custo histórico, desde que as informações geradas por este também sejam confiáveis.

Niyama e Silva (2008), Hendriksen e Van Breda (2007) corroboram o mesmo pensamento e afirmam que os custos históricos irão representar quanto a entidade pagou por determinado ativo. Nesse caso, o ativo será mensurado pelos valores pagos na época da aquisição, possuindo uma relação direta com o fluxo de caixa. O custo histórico torna-se mais objetivo, verificável e irá representar o valor com que o ativo foi adquirido, porém, o valor pode deixar de ter representatividade no decorrer do tempo. Isso pode acontecer pela alteração na expectativa de benefícios econômicos futuros, pela redução da vida útil do ativo, ou ainda em razão da obsolescência.

\section{Planejamento na atividade agrícola}

A atividade rural caracteriza-se como a exploração das atividades agrícolas, pecuárias, extração e exploração vegetal e animal, exploração da apicultura, avicultura, suinocultura, sericicultura, piscicultura, e outras de pequenos animais; a transformação de produtos agrícolas ou pecuários, realizada pelo agricultor ou criador, com o uso de equipamentos e utensílios usualmente empregados nas atividades rurais, utilizando matéria-prima produzida na área explorada (ZANLUCA, 2017). 
O produtor rural deverá estar atento às tarefas relacionadas ao planejamento, organização, orientações sobre como dirigir seus colaboradores diretos e exercer sempre um controle administrativo. Deve, além disso, apresentar planos e orçamentos que permitam o bom andamento da atividade, uma vez que o planejamento e a elaboração de programações anuais servirão de base para o orçamento, auxiliando na previsão das necessidades, na geração de recursos e no controle do andamento (CREPALDI, 2005).

Segundo Souza e Clemente (2008), ao tomar decisão sobre quanto deve ser plantado e qual a área envolvida no projeto agrícola, é necessário identificar o número de fatores, técnicas e metodologias possíveis de ser aplicadas, de maneira que se possa avaliar a atratividade desses investimentos até a projeção de cenários com riscos e incertezas.

Nota-se que a maioria dos produtores rurais não possui planejamento em suas atividades rurais tanto em curto, médio ou até longo prazos. Muitas vezes, acontece de apenas apresentar intenções, comentando as suas deficiências e necessidades, mas não programam os seus investimentos nem elaboram seu fluxo de caixa (RATKO, 2008).

Para Oliveira (2010), planejar é o ato de analisar todas as informações obtidas no passado, no presente e as previsões para o futuro, para que assim se tenha a formação de um curso a ser seguido para alcançar todos os objetivos. Ou seja, planejar é procurar elaborar antes as ações futuras, ação que possibilitará ao produtor ter seus objetivos mais claros, podendo, dessa forma, promover uma melhor coordenação de seus esforços, para alcançar melhores resultados.

Segundo o autor, o planejamento deve estar de forma clara, pois irá determinar de que maneira o objetivo deverá ser alcançado. É necessário um planejamento global, com um cronograma geral de todas as atividades em mãos. Esse planejamento precisa ser dinâmico e contínuo para evitar problemas e prejuízos; precisa ser flexível para todas as situações que apareçam e deverá reduzir ao máximo a variabilidade da previsão.

Segundo Marion (2005), é necessário também identificar o tipo de cultura a ser explorada, ou seja, cultura permanente ou cultura temporária, haja vista cada uma ter diferentes métodos quanto ao plantio, manutenção, colheita e revenda.

\section{Culturas temporárias e culturas permanentes}

Seguindo os preceitos de Marion (2010), as culturas temporárias são aquelas sujeitas ao replantio após a colheita, normalmente possuem um período de vida curto. Por ser a mais escolhida e utilizada pelos pequenos produtores rurais, será a mais enfatizada nesta pesquisa.

Conforme o autor, após a colheita, essas culturas são arrancadas do solo para que seja feito um novo plantio. Como exemplos dessas culturas estão: soja, milho, arroz, feijão, batata, entre outras.

$\mathrm{O}$ autor afirma que os gastos não identificados com a cultura devem ser contabilizados como “despesa do período", e não acumulados em estoque.

Nas culturas temporárias, os custos com a formação são, por exemplo, os custos com todo o plantio, adubações, sementes, mão de obra, calcário, entre outros. Custos com a colheita, com a mão de 
obra, combustível etc., serão contabilizados no Ativo Circulante, na conta "Culturas Temporárias" e em uma subconta "Culturas em Formação", as quais serão classificadas de Estoque (MARION, 2002).

A colheita da cultura temporária é considerada a etapa final da cultura. Após a colheita de uma, iniciam-se os preparativos para o plantio de outra safra.

Crepaldi (2009), Marion (2010) e Rodrigueset al. (2012) comentam que as culturas permanentes têm capacidade de produzir mais de uma vez durante sua vida útil, não estando sujeitas ao replantio após a colheita, ou seja, permanecem no solo e proporcionam mais de uma produção. Às culturas permanentes é atribuída uma duração mínima de quatro anos. Entre os exemplos dessa cultura estão cafeicultura, canade-açúcar, laranjeira, maça, goiaba.

Assim, conforme dados do Instituto Brasileiro de Geografia e Estatística (IBGE, 2017), o município de Tanque D’Arca, localizado na região Nordeste do país, apresenta em relação às lavouras temporárias, 244 hectares de área plantada, 244 hectares de área colhida, e obtém um valor de 1.215 da produção das lavouras temporárias. Tais números evidenciam a relevância do cultivo desse tipo de cultura para o crescimento econômico e social do município. Entre os principais produtos das lavouras temporárias, plantados e colhidos na região, estão batata-doce, amendoim, abacaxi, cana-de-açúcar, feijão, mandioca e milho.

\section{Procedimentos metodológicos}

A pesquisa caracteriza-se como exploratória e descritiva, pois buscará evidenciar a importância da contabilidade no âmbito rural, proporcionando uma maior familiaridade e tornando explícito o problema em questão. É também explicativa, uma vez que busca identificar e entender os fatores que têm causado a não utilização da contabilidade por parte dos pequenos produtores, conhecendo assim a sua realidade (GIL, 2010).

Esta pesquisa classifica-se como uma pesquisa de campo, a qual, para Silva (2003), consiste na coleta direta de informação no local em que acontecem os fenômenos. Nesse caso, buscou-se descobrir qual o conhecimento do pequeno produtor sobre a contabilidade e, caso se aproprie dessa ciência, de que forma ela vem sendo utilizada.

A abordagem deste estudo é quantitativa, um método que, conforme Gonçalves (2005), remete a uma explanação das causas, por meio de medidas objetivas, testando hipóteses ou utilizando basicamente estatísticas. Considerando que os resultados obtidos no estudo consistiram em identificar a percepção de como a contabilidade é vista e utilizada pelos pequenos produtores, ressalta-se que foi utilizada apenas a estatística descritiva.

O procedimento de coleta de dados ocorreu por meio de aplicação de um questionário semiestruturado contendo perguntas abertas e fechadas, relativas ao perfil dos pequenos produtores, às características da propriedade, seus devidos conhecimentos sobre a contabilidade e quais as ferramentas utilizadas. Em seguida, passou por um pré-teste com um profissional da área, e dos respondentes, para identificar e diminuir erros. Logo após, realizou-se o censo com a aplicação dos questionários entre os produtores rurais, de modo a obter informações úteis e relevantes para a confecção da análise. 
Foi escolhido como campo de estudo um sítio localizado no povoado Cabeça D’antas, pertencente ao município de Tanque D’Arca, no agreste alagoano. A localidade é formada por pequenos agricultores rurais, os quais exercem suas atividades agrícolas como forma de subsistência. A escolha do local justifica-se pela conveniência na coleta dos dados. A amostra desta pesquisa foi composta pelos produtores que aceitaram responder ao questionário.

\section{Análise e discussão dos resultados}

Para melhor compreensão dos resultados alcançados nesta pesquisa, os dados serão apresentados de forma geral e específica, com o perfil do produtor e de sua propriedade, sua percepção sobre a contabilidade e ferramentas utilizadas. As informações baseiam-se nas respostas dos produtores rurais ao questionário.

Os entrevistados caracterizam-se como pertencentes ao sistema de agricultura familiar ou de subsistência, no qual desenvolvem atividades agrícolas. A pesquisa aconteceu no Sítio Cabeça D'antas, localizado no município de Tanque D’Arca, Alagoas, que possui em média cerca de 80 habitantes, dos quais apenas 20 responderam ao questionário.

Tabela 1 - Perfil dos entrevistados.

\begin{tabular}{|c|c|c|c|c|c|c|c|c|}
\hline Sexo & & Idade & & & Nível de es & aridade & & \\
\hline Feminino & Masculino & $20 \mathrm{a} 30$ & $31 \mathrm{a} 40$ & $\begin{array}{c}\text { Acima de } \\
41\end{array}$ & $\begin{array}{c}\text { Fundament } \\
\text { al }\end{array}$ & Médio & Superior & $\begin{array}{c}\text { Pós- } \\
\text { Graduação }\end{array}$ \\
\hline $33,33 \%$ & $63,67 \%$ & $14,29 \%$ & $14,28 \%$ & $71,43 \%$ & $71,43 \%$ & $28,57 \%$ & ------ & ----- \\
\hline
\end{tabular}

Fonte: Dados da pesquisa (2019).

Com base nos dados da Tabela 1, é evidente a predominância do masculino entre os produtores rurais, 63,67\%. Mais da metade dos pesquisados são pessoas com mais de 40 anos de idade. Destaca-se também o grande número de pessoas apenas com ensino fundamental. Na região rural estudada, 71,43 \% concluíram apenas o ensino fundamental e, entre estes, alguns nem chegaram a concluir esse nível de ensino. Segundo os próprios produtores, isso decorre não apenas de um problema antigo, a falta de oportunidades, mas também pelo fato de serem famílias de baixa renda. Com pouca idade, eram obrigados a deixar os estudos para trabalhar e, assim, ajudar no sustento da família. O abandono dos estudos, segundo informam os respondentes, também ocorreu para poder se dedicar ao trabalho, à agricultura e, assim, conseguir seu sustento e o da família.

Tabela 2 - Caracterização da propriedade.

\begin{tabular}{cccccc}
\hline $\begin{array}{c}\text { Tamanho da } \\
\text { propriedade }\end{array}$ & $\%$ & $\begin{array}{c}\text { Objetivo pelo qual } \\
\text { produz }\end{array}$ & $\%$ & \multicolumn{3}{c}{$\begin{array}{c}\text { Tempo como } \\
\text { agricultor }\end{array}$} \\
\hline Até 5 tarefas & $61,90 \%$ & Subsistência & $28,57 \%$ & Até 5 anos & $4,76 \%$ \\
Até 10 tarefas & $14,29 \%$ & Mercado & - & Até 15 anos & $19,05 \%$ \\
Mais de 10 tarefas & $23,81 \%$ & Ambos & $71,43 \%$ & Mais de 15 anos & $76,19 \%$ \\
\hline Total & $100 \%$ & & $100 \%$ & & $100 \%$ \\
\hline
\end{tabular}

Fonte: Dados da pesquisa (2019). 
Outro fato relevante, apontado na Tabela 2, é que 76,19\% dos pesquisados atuam na agricultura familiar há mais de 15 anos. Isso demonstra que boa parte deles nasceu no seio rural e continua sem provocar a migração para a cidade. Mostra também que começaram a trabalhar nesse ramo desde a adolescência.

Também fica evidente que $71,43 \%$ desses agricultores utilizam suas terras e propriedades para cultivo de culturas temporárias que servirão tanto para sua subsistência quanto para a comercialização no mercado, proporcionando-lhes uma renda extra. Esses produtos são comercializados tanto no comércio local como em cidades vizinhas, como Palmeira dos Índios, Arapiraca, Belém, Taquarana.

Na Tabela 3 estão evidenciados os principais produtos cultivados pelos produtores, conforme eles próprios informaram. Vale salientar que os percentuais apresentados estão relacionados ao quantitativo de agricultores que afirmou plantar os produtos em destaque.

Tabela 3 - Produtos cultivados pelos produtores.

\begin{tabular}{ccccccc}
\hline Feijão & Milho & Mandioca & Inhame & Abóbora & Batata & Frutas e Verduras \\
\hline $85,71 \%$ & $85,71 \%$ & $28,57 \%$ & $42,86 \%$ & $28,81 \%$ & $47,61 \%$ & $61,90 \%$ \\
\hline
\end{tabular}

Fonte: Dados da pesquisa (2019).

Conforme dados da Tabela 3, os principais produtos cultivados nas propriedades rurais são: feijão, milho, frutas e verduras e batata. Em sua maioria, são destinados tanto para o autoconsumo quanto para a comercialização.

Nota-se que o desenvolvimento dos processos nessas propriedades é complexo. Isso acontece devido à adaptação das necessidades da família, ou seja, seu estilo de vida, aos requisitos e exigências do mundo dos negócios, que seriam os objetivos comerciais.

Em conversa com esses produtores, eles relataram que se trata de um ambiente cheio de incertezas e mudanças, o qual exige também informações precisas e disponíveis para a realização dos processos de decisão, e não apenas a sua experiência como produtor rural.

Tabela 4 - Percepção sobre contabilidade e suas ferramentas.

\begin{tabular}{ccccccc}
\hline \multicolumn{3}{c}{ Conhecimento sobre acontabilidade } & \multicolumn{3}{c}{ Utilização de métodos contábeis } \\
\hline Nenhum & Pouco & Médio & Muito & Sim & Não \\
\hline $85,71 \%$ & $14,29 \%$ & ----- & ---- & ---- & $100 \%$ \\
\hline
\end{tabular}

Fonte: Dados da pesquisa (2019).

Com base na Tabela 4, é possível observar que "dentro da porteira", o agricultor conhece muito bem o seu ambiente e o seu trabalho, pois vive isso na prática. No entanto, quando o assunto é tudo aquilo que se passa "fora da porteira", tudo se torna mais complexo, difícil e desconhecido. Os dados mostram que $85,71 \%$ dos agricultores não conhecem sobre a contabilidade e $100 \%$ dos entrevistados não utilizam nenhum método contábil.

Em uma pesquisa sobre a contabilidade como uma grande ferramenta para a atividade rural, Hofer, Borilli e Philippsen (2006) concluem que essa ciência é um instrumento muitas vezes empregado somente para fins fiscais. A pesquisa também revelou o pouco interesse dos proprietários rurais para 
utilizar a contabilidade e, assim, dispor de um grande mecanismo na tomada de decisões. Os profissionais mostraram-se interessados em fazer a contabilidade rural, por outro lado, admitem a carência de qualificação para atuar nessa área da ramificação contábil.

Tabela 5 - Percepção sobre contabilidade e suas ferramentas.

\begin{tabular}{|c|c|c|c|c|c|}
\hline \multicolumn{2}{|c|}{$\begin{array}{l}\text { Conhecimento sobre métodos de } \\
\text { mensuração }\end{array}$} & & \multicolumn{3}{|c|}{ Elaboração dos preços de venda } \\
\hline $\operatorname{Sim}$ & Não & Mercado & Custos & Outros & $\begin{array}{l}\text { Não produz para } \\
\text { venda }\end{array}$ \\
\hline ------ & $100 \%$ & $71,43 \%$ & ------ & $\begin{array}{ll}----- \\
-1\end{array}$ & $28,57 \%$ \\
\hline
\end{tabular}

Fonte: Dados da pesquisa (2019).

Diante dos dados da Tabela 5, percebe-se que esses produtores não estabelecem metas claras, não elaboram projetos, tampouco empregam métodos de mensuração para um maior controle de sua produção e comercialização. O total de entrevistados, 100\%, declara não conhecer esse método e, por isso, opta sempre por aquilo que o mercado dita e impõe. Ressalta, além disso, que é melhor vender por um preço menor do que não conseguir vender.

Os respondentes afirmam ainda que deixam as coisas acontecerem naturalmente e quando surgem as oportunidades simplesmente fazem o que precisa ser feito, agindo, na maioria das vezes, pela intuição. Ressaltam também que quando ocorrem imprevistos como, por exemplo, chuvas torrenciais, secas prolongadas, ou mesmo desastres ambientais, eles não fazem a mensuração das culturas e, por essa razão, têm grandes prejuízos, ou seja, vendem suas culturas por um preço mais baixo, quando ainda sobra algo para a comercialização.

Com base nas informações apresentadas, observa-se que os agricultores não possuem conhecimento sobre formação de preço de venda, reconhecimento de perdas ocorridas com as mudanças climáticas. A formação do preço acontece desordenadamente, o que é prejudicial não somente para os pequenos agricultores, mas também para a economia local, podendo assim causar prejuízos que, por vezes, podem passar despercebidos.

O procedimento utilizado por esses pequenos agricultores para a precificação, etapa muito importante na concepção do produto final, não compõe todas as informações necessárias para a correta formação de preço, fundamentais para que o pequeno produtor reconheça as perdas afetadas pelas mudanças climáticas na formação do preço de venda de suas culturas. Tal informação corrobora o estudo de Silva et al. (2014), os quais concluíram que os agricultores produzem de forma rudimentar, ou seja, não existem conhecimentos técnicos para analisar a produção, os custos e despesas, o que define o preço de venda.

Os produtores acompanham sempre os valores de mercado para poder determinar o preço de seus produtos. E ressaltam sobre a grande oscilação conforme a época de venda de cada produto, ou seja, não existe um preço fixo, já que cabe ao mercado defini-lo.

Importante frisar que a formação do preço de venda é utilizada por todas as empresas do mercado, pois, tudo o que se vende ou negocia, necessita de um preço, ou seja, de um valor monetário (IUDÍCIBUS; MARTINS; GELBCKE; 2000). Para o autor, na economia de mercado, os preços

\begin{tabular}{l|c|c|c|c|c|c|c|c|} 
Cadernos de Ciências Sociais Aplicadas & ano XVI & vol. 16 & $n^{\circ} 28$ & págs. 130-144 & jul./dez: 2019 & UESB & Vitória da Conquista/BA & pág. 140 \\
\hline
\end{tabular}


decorrem dos mecanismos da oferta e procura, ou seja, o mercado é, de fato, o grande responsável pela fixação do preço, e não os custos de obtenção dos produtos.

Os produtos comercializados, como inhame, milho e feijão, por exemplo, são considerados, por grande parte dos agricultores, de fácil mensuração, ou seja, possuem uma melhor forma de atribuição de valor, pois são de fácil comercialização, e têm alta demanda no mercado. As frutas e verduras são vistas com maior dificuldade para definição de valores, pois dependem muito da qualidade que apresentam. No caso dessas culturas, a qualidade é mais incerta que os outros produtos.

Baseado nesses dados e também nos conhecimentos sobre gestão do segmento apresentados neste trabalho, é possível afirmar que o produtor rural poderia agregar maior valor aos seus produtos se dispusesse de aprimoramento e de maiores informações sobre a gestão do seu próprio negócio, o que salienta a relevância da organização e do conhecimento para o melhor desenvolvimento de quaisquer atividades.

\section{Considerações finais}

Neste estudo, fez-se uma análise sobre o conhecimento e utilização da contabilidade por parte dos pequenos produtores rurais do Município de Tanque D'Arca. Conclui-se que esses produtores tentam buscar informações para poder se aperfeiçoar no desenvolvimento das atividades, embora na maioria das vezes não consigam utilizar essas informações, o que os leva a obter um resultado insatisfatório, que não garante a sustentabilidade e o crescimento do negócio e da produção.

A pesquisa mostra que esses produtores não realizam os princípios básicos de gestão e mensuração das informações contábeis que, segundo Batalha e Silva (2001), compreende a coleta de dados, geração de informações, processo de tomada de decisão e devidas ações.

Outro aspecto relevante é o produtor não realizar um controle rigoroso das receitas e despesas. Isso ocorre devido ao pouco conhecimento sobre como aprimorar a comercialização dos produtos e minimizar os riscos e prejuízos. Uma vez que não sabe avaliar os resultados financeiros obtidos, o produtor consegue apenas visualizar alguns resultados econômicos quando observa melhorias e adquire bens para a propriedade. Para ele, isso significa lucro.

Diante da constatação da falta de conhecimento da contabilidade por parte dos produtores rurais, uma questão pareceu bem pertinente: passar a conhecer sobre essa área e tudo o que a abrange, gestão, receitas, despesas, lucros ou prejuízos. É preciso entender que a contabilidade pode ser aplicada em qualquer meio e ambiente, que traz sempre grandes benefícios para quem a utiliza, e esquecer a ideia de que essa ciência só pode estar presente na região urbana e pode ser aplicada apenas nas grandes empresas.

Diante do objetivo de contribuir com informações acerca da contabilidade e da correta formação do preço de venda das culturas temporárias, sugere-se que os sindicatos e associações de agricultores do Município de Tanque D’Arca passem a ofertar cursos que orientem esses produtores sobre a correta mensuração e precificação dos produtos cultivados. Assim, eles poderão aumentar sua rentabilidade e atingir uma parcela significativa da sociedade pesquisada. 
O presente estudo lança a sugestão de realização de outras pesquisas, para um melhor entendimento sobre a atividade agrícola, voltada à agricultura familiar em outras localidades do país, uma vez que é importante conhecer essas "pessoas invisíveis", as quais contribuem de forma significativa para suas regiões. Identificar as características (climáticas, econômicas ou políticas) das regiões dos pequenos produtores rurais é também um fator de grande relevância para pesquisas futuras.

\section{Referências}

AMARO, H. D.; SOUZA, A.; DA SILVA, E. D. Ativo biológico: conceituação, reconhecimento e mensuração. In: Anais do Congresso Brasileiro de Custos-ABC. 2016.

ARAÚJO, M. J. Fundamentos de agronegócio. São Paulo: Atlas, 2003.

BADEJO, M. S. Análise da agregação de custo e de valor por atividades, em uma cadeia agroindustrial: caso do gado de corte.(Tese de Doutorado em Agronegócios) Centro de Estudos e Pesquisas em Agronegócio, Universidade Federal do Rio Grande do Sul, Porto Alegre, 2005.

BATALHA, M. O.; SILVA, A. L. Gerenciamento de Sistemas Agroindustriais: definições e correntes metodológicas. In: BATALHA, M. O. (Coord.). Gestão Agroindustrial. 2. ed. São Paulo: Atlas, 2001. p. 23-62. ISBN: 85-224-1551-X.

BRASIL, Lei no 11.326, de 24 de julho de 2006. Estabelece As Diretrizes Para A Formulação da Política Nacional da Agricultura Familiar e Empreendimentos Familiares Rurais. Disponível em: <http://www.planalto.gov. br/ccivil_03/_Ato2004-2006/2006/Lei/L11326.htm>. Acesso em: 01 fev. 2019.

CALDERELLI, A. Enciclopédia contábil e comercial brasileira. 28. ed. São Paulo: Cetec, 2003.

CEPEA/ESALQ-USP. Disponível em: < https://www.cepea.esalq.usp.br/br>. Acesso em: 29 outubro 2018.

CREPALDI, Silvio Aparecido, (2005) - Contabilidade Rural: Uma abordagem decisorial,3 ed. São Paulo: Atlas.

CREPALDI, Silvio Aparecido. Contabilidade rural, uma abordagem decisória. 4. Ed. revista, atualizada e ampliada - São Paulo: Atlas, 2006.

CREPALDI, Silvio Aparecido. Contabilidade rural: uma abordagem decisorial. 5.ed. rev., atual. eampl. São Paulo: Atlas, 2009.

CREPALDI, Silvio Aparecido. Contabilidade rural: uma abordagem decisorial. $7^{\mathrm{a}}$ ed., São Paulo: ATLAS, 2012.

GIL, A. C. Métodos e técnicas de pesquisa social. São Paulo: Atlas, 2010.

GONÇALVES, Hortência de Abreu. Manual de metodologia da pesquisa científica. São Paulo, 2005.

HENDRIKSEN, E. S.; BREDA, M. F. V. Teoria da contabilidade. São Paulo: Atlas, 2007.

HOFER, E.; BORILLI, S. P.; PHILIPPSEN, R. B.Contabilidade como ferramenta gerencial para a atividade rural: um estudo de caso. Enfoque: Reflexão Contábil, v. 25, n. 3, p. 5-16, 2006. 
IUDÍCIBUS, S. DE; MARTINS, E.; GELBCKE, E. R. Manual de Contabilidade das Sociedades por Ações. 5. ed. São Paulo: Atlas, 2000.

INSTITUTO BRASILEIRO DE GEOGRAFIA E ESTATÍSTICA- IBGE. Disponível em $<$ https://www.ibge.gov.br/estatisticas-novoportal/economicas/agricultura-e-pecuaria/9117-producaoagricola-municipal-culturas-temporarias-e-permanentes.html? $=\& \mathrm{t}=$ resultados $>$. Acesso em: 08 Novembro 2018.

LIMA, A. P. L.; BASSO, N.; NEUMANN, P. S. Administração da unidade de produção familiar: modalidades de trabalho com agricultores. Ijuí: Unijuí, 2005.

MARION, José Carlos. Contabilidade rural. 7. ed. São Paulo: Atlas, 2002.

MARION, J. C.. Contabilidade rural: contabilidade agrícola, contabilidade da pecuária, imposto de renda pessoa jurídica. 8. ed. São Paulo: Atlas, 2005.

MARION, José Carlos. Contabilidade rural:Contabilidade agrícola, Contabilidade da pecuária, imposto de renda pessoa jurídica. 12.ed. São Paulo: Atlas, 2010.

MINISTÉRIO DO DESENVOLVIMENTO AGRÁRIO - MDA. Disponível em $<$ http://www.mda.gov.br/sitemda/noticias/o-que-\%C3\%A9-agricultura-familiar>. Acesso em: 29 outubro 2018.

NAGATSUKA, D. A. S; TELES, E. L. Manual de contabilidade introdutória. São Paulo: Thompson/Pioneira, 2002.

NIYAMA, J. K.; SILVA, C. A. T. Teoria da contabilidade. São Paulo: Atlas, 2008.

OLIVEIRA, N. C. Contabilidade do Agronegócio: teoria e pratica. Curitiba: Juruá, 2010.

POLATO, R. Gestão no setor agrícola exige aperfeiçoamento, 2006.

PROGRAMA NACIONAL DE FORTALECIMENTO DA AGRICULTURA FAMILIAR-PRONAF. Disponível em < https://www.bcb.gov.br/pre/bc_atende/port/PRONAF.asp>. Acesso em: 29 outubro 2018.

PRONUNCIAMENTO TÉCNICO CPC 29 - Ativos Biológicos e Produto Agrícola. Disponível em: http://www.cpc.org.br/pdf/CPC_29.pdf.

RATKO, A. T. Contribuições da Contabilidade Rural Para Propriedade Agrícola de Pequeno Porte. Pato Branco, 2008.

RODRIGUES, A. O.et al.Contabilidade Rural. 2.ed. São Paulo: IOB, 2012.

SANTOS, G. J.; MARION, J. C.; SEGATTI, S. Administração de custos na agropecuária. 3 ed. São Paulo: Atlas, 2002.

SILVA, F. C. B.; FERRO, A. M. Á.; SILVA, J. C.; SILVA, M. R.; SOUZA, M. I. C. P.; PREÇO DE VENDA E AS MUDANÇAS CLIMÁTICAS: Um estudo sobre as influências climáticas na formação do preço de venda do feijão na cidade de São Sebastião - In: Anais. CONINFA, 2014.

SILVA, A. C. R. Metodologia da pesquisa aplicada à contabilidade: orientações de estudos, projetos, artigos, relatórios, monografias, dissertações, teses. São Paulo: Atlas, 2003.

SOUZA, A.; CLEMENTE, A. Decisões financeiras e análise de investimentos. 6. ed., São Paulo: Atlas, 2008. 
VEIGA, J. E DA . Cidades imaginárias: o Brasil é menos urbano do que se calcula . São Paulo: Autores Associados, 2002.

WANDERLEY, Carlos Alexandre Nascimento; SILVA, Anderson Chaves; LEAL, Rodrigo Barreiros. Ativos Biológicos e Produto Agrícola: Uma análise das Principais Empresa do Agronegócio Brasileiro. 2012.

ZANLUCA, J. C. A Contabilidade nas Operações Rurais. Disponível em:<http://www.portaldecontabilidade.com.br/tematicas/contabilidaderural.htm>Acesso em: 07 Agosto 2018.

Recebido em: 06/05/2019.

Aprovado em: 07/10/2019. 